\title{
Para além do exótico ou bélico: cinemas e histórias do país de Tagore e Jamal Malik
}

Maria Ignês Carlos Magno

Doutora em Ciências da Comunicação pela ECA/USP.

Professora do mestrado em Comunicação da Universidade Anhembi Morumbi

e da Fundação Escola de Sociologia e Política de São Paulo.

E-mail: unsigster@gmail.com

Resumo: a autora propõe para esta edição da revista reflexões a partir do filme Quem quer ser um milionário?, de Danny Boyle, com roteiro de Simon Beaufoy, adaptado da novela de Vikas Swarup, Q \& A. O objetivo é recuperar aspectos da história e da cultura indiana a partir dos seus cinemas.

Palavras-chave: cinema, Índia, história, linguagem, ficção.
Abstract: The author proposes reflections on the motion picture Who Wants to Be a Millionaire?, by Danny Boyle and screenplay by Simon Beaufoy, adapted from the novel by Vikas Swarup, $Q$ \& A. The objective is to recover aspects from the Hindu history and culture using the history of its cinemas.

Keywords: cinema, India, history, language, science.

Deixa a cantilena, o cântico e a recitação de contas de rosário! A quem veneras neste recanto solitário e escuro dum templo de portas fechadas? Abre teus olhos e vê que teu Deus não está diante de ti! Ele está onde o agricultor está lavrando o chão duro e onde o pedreiro está rachando pedras. Ele está com eles no sol e na chuva, e sua roupa está coberta de poeira. Remove teu manto sagrado e como Ele desça para o chão empoeirado!

Libertação? Onde se encontra esta libertação? Nosso mestre assumiu pessoalmente com alegria os vínculos da criação;

Ele está vinculado a nós para sempre. Sai de tuas meditações e deixa de lado tuas flores e o incenso!

Que mal há se tuas roupas ficam gastas e manchadas? Encontra-o e fica com Ele na faina e no suor de tua face ${ }^{1}$.

1. RABINDRANATH, Tagore. Coletânea de poesias. Disponível em: <http://www.cuidardoser. com.br/coletanea-tagore. htm $>$. 
comunicação \& educação • Ano XIV • Número 3 • set/dez 2009

\author{
O cinema existe há mais de dez mil anos \\ nas mentes dos seres humanos, \\ na forma de processos associativos, \\ devaneios, experiências sensíveis \\ e fluxos de consciência. \\ A descoberta da técnica apenas \\ o tornou possível ${ }^{2}$.
}

Histórias e tempos separam a Índia do poeta, músico e filósofo Rabindranath Tagoe e a da personagem do filme Quem quer ser um milionário?, Jamil K. Malik. Histórias e tempos separam a Índia das Mil e uma noites da Índia potência nuclear e terceira força militar do planeta.

A Índia de Tagore, integrada aos mercados mundiais desde 1870, pertenceu oficialmente ao Império Britânico de 1876 a 1947, quando o movimento da resistência não violenta liderado por Mahatma Gandhi, Vallabhbhai Patel e Jawaharlal Neru resultou na independência da Índia.

A Índia de Malik, considerada a maior democracia do Sul da Ásia, que há muito deixou de ser um simples ator regional entre os maiores da economia mundial, é hoje uma das grandes potências econômicas do mundo globalizado. Tagore nasceu em Calcutá, foi educado na tradição indiana e completou seus estudos e formação na Inglaterra. Voltou para a Índia em 1890, fundou a escola de filosofia em Santiniketan, cuja proposta era ensinar as culturas e as filosofias do Ocidente e do Oriente. Amigo de Mahatma Gandhi, participou ativamente do movimento nacionalista indiano, ao mesmo tempo que escrevia sua obra poética em língua bengali. Reconhecido e premiado no Ocidente, sua obra versava sobre temas religiosos, sociais e políticos. Posicionado politicamente, rejeitou o título de Sir em protesto à política britânica no Punjab. Poeticamente, dizia que o homem só ensina bem o que para ele tem poesia. Poesia e prosa comprometidas com a humanidade.

Malik, na ficção cinematográfica, nasceu em uma das favelas de Bombaim e vive os paradoxos dos efeitos da globalização, em que a economia atingiu uma taxa de crescimento não imaginado e, ao mesmo tempo, abriu um fosso social também crescente. O jovem personagem é contemporâneo da cultura do consumo atravessada por anúncios da Coca-Cola, da MTV, dos computadores, das multinacionais instaladas por todas as regiões, das castas e das tradições, dos híbridos culturais - como, por exemplo, o "Bhangra pop, que mescla a música folclórica do Punjab rural com o reggae da Índia ocidental, e chega à juventude indiana por intermédio da última geração da diáspora indiana em Birmingham e Londres" ${ }^{-}$, das diferenças religiosas, da Star TV, da Hindi Films.

A despeito dos diferentes tempos históricos que separam os personagens dos estereótipos políticos e culturais construídos em torno do país, personagem real e ficcional têm em comum uma história ainda pouco conhecida: a da indústria cinematográfica da Índia. Pensando nessa Índia que está além do exótico ou do bélico, trouxemos o polêmico filme Quem quer ser um milionário?, de Danny Boyle, como pretexto para pesquisar os cinemas e as complexas histórias desse vasto continente. 


\section{O FILME: QUEM QUER SER UM MILIONÁRIO?}

De acordo com a sinopse, Jamal K. Malik (Dev Patel) é um jovem que trabalha servindo chá em uma empresa de telemarketing. Sua infância foi difícil, tendo que fugir da miséria e da violência para conseguir chegar ao emprego atual. Um dia ele se inscreve no popular programa "Quem quer ser um milionário?" (Who Wants To Be A Millionaire? ou Show do Milhão, aqui no Brasil). Inicialmente desacreditado, ele encontra em fatos de sua vida as respostas para as perguntas feitas no programa. Preso sob suspeita de ter trapaceado, ele conta à polícia sua incrível história de vida como menino de rua, e sobre a garota que tanto ama, mas que também perdeu. Mas o que uma criança sem nenhum interesse em dinheiro estaria fazendo nesse programa? E como é possível que ele soubesse todas as respostas? ${ }^{4}$

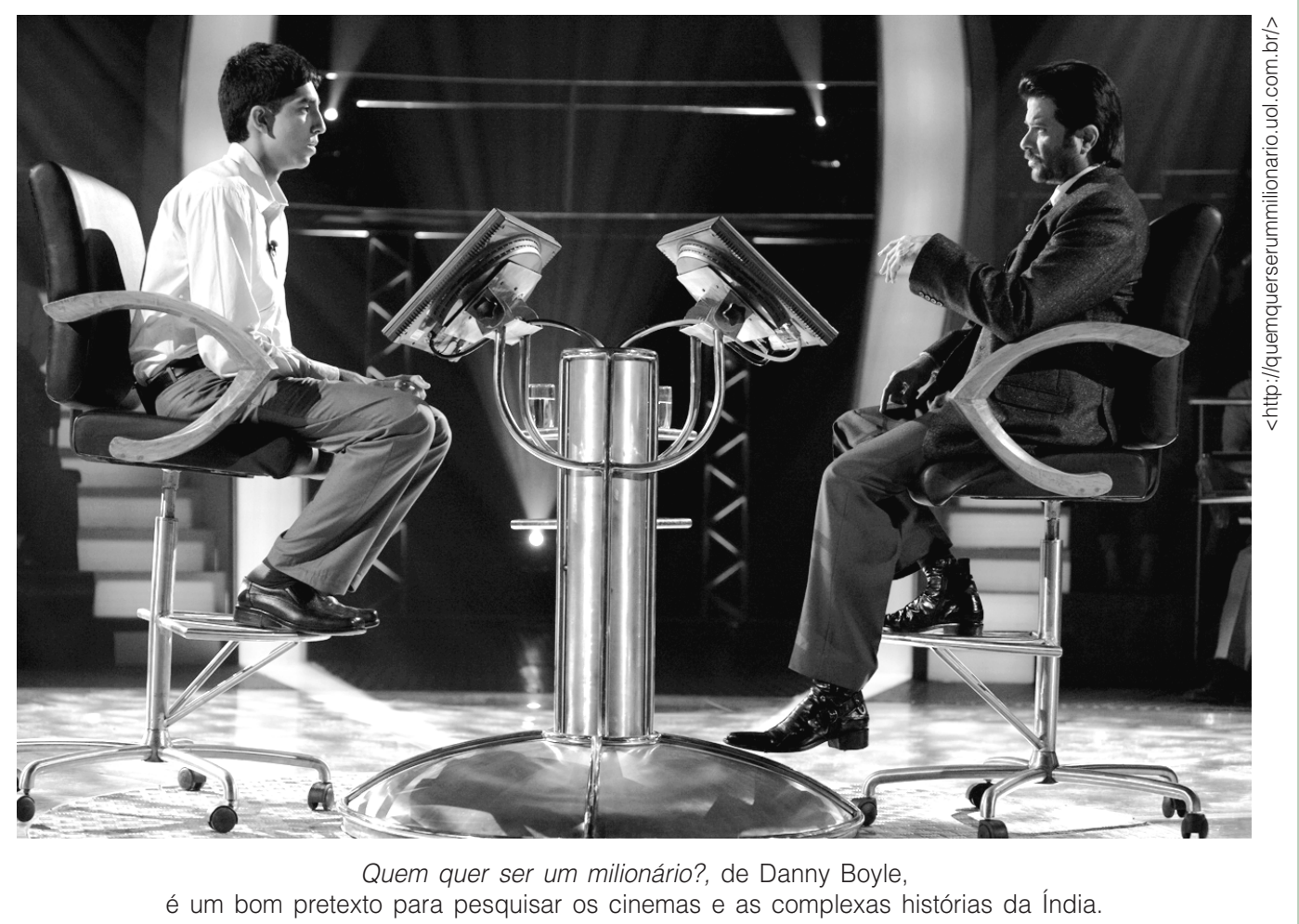

\section{FICHA TÉCNICA}

Título original: Slumdog millionaire

Direção: Danny Boyle

Roteiro: Simon Beaufoy, baseado no livro de Vikas Swarup

Gênero: Drama

Fotografia: Anthony Dod Mantle

Música: A. R. Rahman

Produção: Christian Colson

Edição: Chris Dickens

Duração: $120 \mathrm{~min}$

Ano de lançamento: 2008

4. Disponível em: <http:// quemquerserummilionario.uol.com.br/s. 
Quem quer ser um milionário? recebeu oito prêmios da Academia de Hollywood em 2009, provocando polêmicas e críticas de toda natureza. Uma delas repousa sobre a estrutura do roteiro que Simon Beaufoy fez da novela de Vikas Swarup, $Q \mathcal{E} A$. Swarup nasceu em Allahabad, na Índia, no seio de uma família ilustre. Frequentou a Universidade de Allahabad, onde se destacou como campeão de debates, vencendo diversas competições nacionais. Após a conclusão do curso, seguiu carreira diplomática, tendo sido destacado para países como Estados Unidos, Turquia, Etiópia e Reino Unido. Trabalha atualmente no Ministério dos Negócios Estrangeiros em Nova Délhi ${ }^{5}$. Quem quer ser bilionário?, o seu primeiro romance, foi adaptado ao cinema, venceu quatro Globos de Ouro e concorreu a dez estatuetas do Oscar. Se as imprecisões e os defeitos do roteiro são perceptíveis ao mais leigo dos espectadores, são também notáveis as qualidades da montagem, da fotografia e da música. Como as possibilidades de estudarmos um filme tanto pela gramática como pela temática são inúmeras, e não necessariamente um filme vale apenas pela sua perfeição, a proposta para esta seção é a de recuperar aspectos da história e da cultura indiana a partir dos seus cinemas.

\section{ÍNDIA: ALI A HISTÓRIA DO CINEMA É BEM ANTIGA}

O filme Quem quer ser um milionário?, como sabemos, é uma produção inglesa, rodado na Índia, mais especificamente em Bombaim, e totalmente falado em inglês. Informações que à primeira vista não nos causam estranheza, afinal a Índia foi por duzentos anos colônia inglesa e o idioma inglês é comum entre os indianos.

Estranho talvez seja o fato de que não podemos falar de um cinema indiano e de só nos referirmos ao cinema na Índia no plural: cinemas indianos. Ou, refinando um pouco mais: cinemas regionais, produzidos, em sua maioria, com capitais próprios e falados em suas línguas locais. Línguas e não dialetos, como poderíamos supor. Isso porque "cada indústria se define de acordo com sua língua. Falamos em cinema bengalês, cinema telugu, cinema malayalam, cinema tâmil, cinema marathi, cinema punjab, cinema híndi” ${ }^{6}$, para citar os que se destacam na produção interna. Dessas línguas todas, para termos um exemplo da complexidade linguística da Índia, apenas o híndi e o marathi têm o mesmo alfabeto davanagari. Todas as outras possuem seu próprio alfabeto. Não bastasse, além dos dois principais troncos linguísticos: o sânscrito do norte, e o dravidiano do sul, há o urdu, um dialeto híndi que é uma variação do alfabeto árabe.

Se, diante disso, não podemos continuar pensando que todo cinema produzido na Índia é de Bollywood, mistura de Bombaim com Hollywood, porque, apesar de este cinema ser o mais conhecido no Ocidente, é um dentre outros regionais, resta-nos interrogar sobre a história dos outros cinemas produzidos naquele país e as relações que se estabelecem entre essas indústrias e as histórias da Índia e do Ocidente. 
Lá no continente indiano o cinema chegou bem cedo, 1890, mais especialmente em Calcutá, sede da capital do governo britânico nas Índias. Em 1896, o cinema foi mostrado pelos operadores da casa de Lumière, além da Índia, para os povos que pertenciam ao Império Britânico: o Paquistão, a Birmânia e o Sri-Lanka (Ceilão). "Entre 1913 e 1923, D. G. Phalké realizou Raja Harischandra, cujo êxito lhe deu condições para fundar a Hindustan Film Co. Construiu um estúdio em Nasik, na região de Bombaim"7, que não parou de crescer até 1931, quando sofreu uma crise, mas sem abalar o progresso nos aspectos artísticos.

Dos primeiros filmes com temáticas religiosas ou místicas, passando pelos dramas clássicos ou da literatura moderna, como Balidan, de Tagore, ou Andharey Alo, do romancista bengalês Sarht Sandra Chatterjee, até os que condenavam sacrifícios rituais de animais, a produção cinematográfica nacional crescia, assim como as reivindicações políticas nacionais que encontravam ecos nas obras dos realizadores. Uma delas, o filme $A$ cólera, que preconizava a amizade entre muçulmanos e hindus, foi proibida porque o protagonista se parecia demais com Mahatma Gandhi .

Com a introdução do cinema falado, além da dança e da música ser um dos focos centrais dos filmes, começou um movimento pela generalização da língua híndi em todas as produções em oposição ao inglês, na época falado pela elite. Ainda de acordo com Georges Sadoul:

[...] os cinemas nacionais multiplicaram-se e começaram a utilizar uma dezena de línguas diferentes, que lhes permitiriam atingir mais vasto público. Formaram-se nessa altura três grandes centros de produção cinematográfica: no oeste, Bombaim, Poona e Kholapur, para filmes híndi, marata e gujerat; no leste, Calcutá, para filmes em bengali; no sul, Madras, Coimbatore, Salem, etc., para filmes tâmil, telegu, malayalam..., línguas dravídicas sem relação nenhuma com as línguas do norte, derivadas do sânscrito ${ }^{9}$.

Embora a produção cinematográfica regional ganhe força e até supere a de Bombaim em número de filmes, de público e de indústria nos dias atuais, é interessante continuarmos com um pouco mais das histórias que rodeiam Bombaim/Mumbai, ainda hoje um dos maiores centros comerciais e cosmopolitas da Índia. E também porque o filme aqui proposto tem a cidade/capital do estado de Maharashtra, localizada na ilha de Salsete, na desembocadura do rio Ulhas, como local da ficção cinematográfica.

Se recuperarmos, mesmo que cronologicamente, dados da história de Bombaim, podemos entender por que ela sempre esteve envolvida com os processos de globalização. Estende-se desde a conquista e estabelecimento das bases portuguesas em 1509, em Goa, Damião, Diu e Bombaim, à transferência da sede da Cia. das Índias Orientais de Surate para Bombaim em 1678, à abertura da ferrovia ligando Bombaim a Thane, em 1853, até a abertura do Canal de Suez, em 1869, que transformou Bombaim em um dos maiores portos marítimos do Mar Arábico. Podemos compreender também o seu cosmopolitismo e destaque entre as demais cidades indianas, incluindo Calcutá.
7. SADOUL, Georges. História do cinema mundial. Lisboa: Livros Horizonte, 1983. p. 525, v. III.

8. Ibid., p. 527.

9. Ibid., p. 527 
comunicação \& educação • Ano XIV • Número 3 • set/dez 2009

Bombaim também foi uma importante base do movimento de independência indiano, especialmente o movimento "Deixem a Índia", iniciado por Gandhi em 1942. E, após a independência da Índia em 1947, passou a ser a capital do estado de Maharashtra. A década de 1950 foi o período de crescimento e expansão da cidade até seus limites atuais.

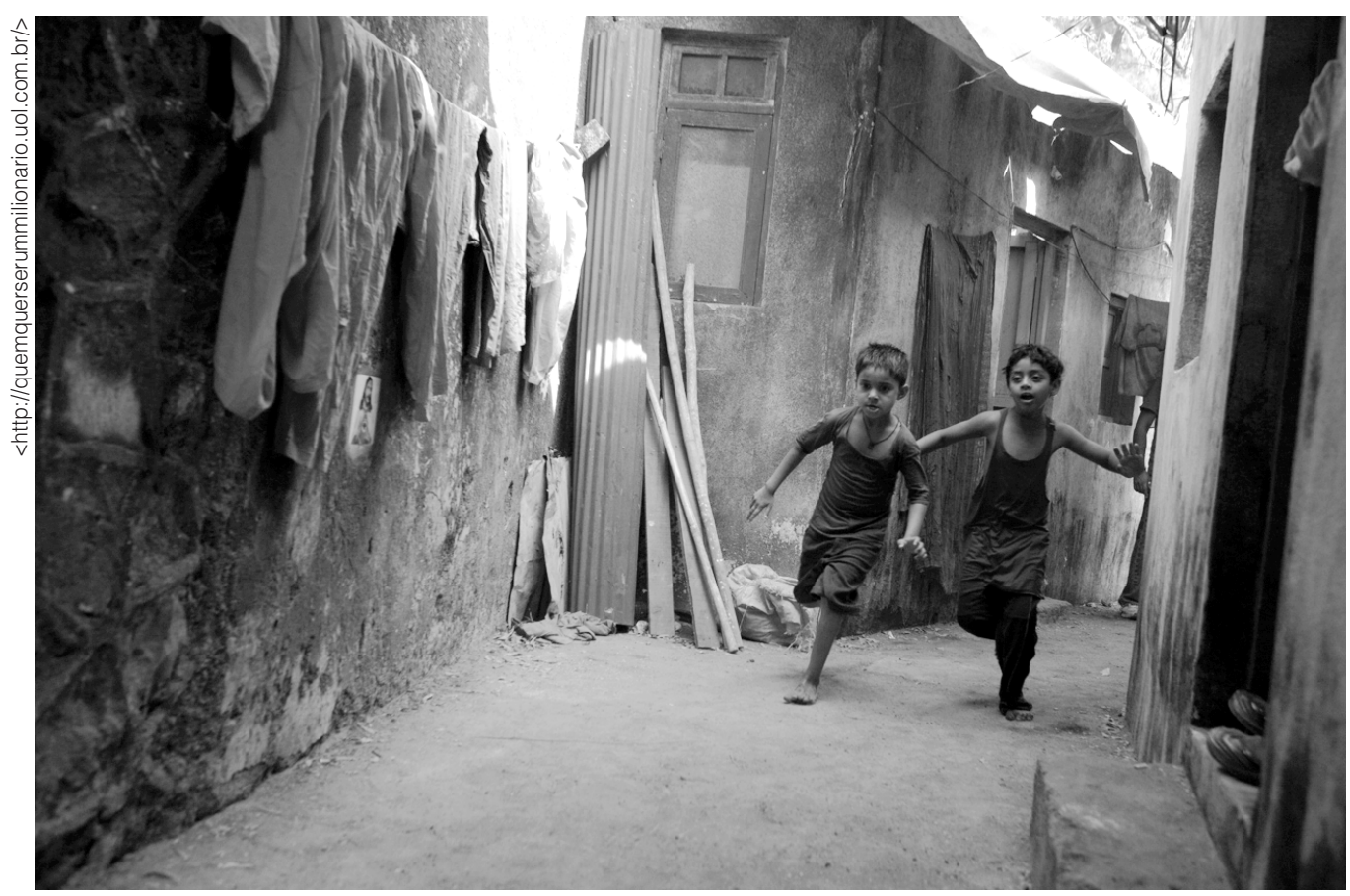

Órfão, Jamal divide com outras crianças a vida miserável das favelas de Bombaim.

Durante a história contada por Jamal Malik, conseguimos ver como Bombaim está dividida em duas áreas distintas: a cidade e os subúrbios que se constituem em distritos separados pertencentes ao estado. Na sequência em que os irmãos conversam e olham do alto de um prédio a transformação da antiga favela onde moravam quando crianças em um complexo residencial, fica registrado o surto de construção que a cidade vive desde o final de 1970.

No início do filme, Jamal vê o local onde vive ser atacado e sua mãe ser morta por pessoas contrárias aos muçulmanos que moram nas favelas de Bombaim; não há uma explicação sobre o que significa aquilo na narrativa. Embora a ficção não tenha que explicar a história, é importante sabermos que aquela sequência é parte de uma das realidades de Bombaim e da Índia atual.

O desenvolvimento econômico da cidade trouxe riquezas, oportunidades de trabalho e uma melhora razoável das condições de vida. A cidade do comércio e do entretenimento, como é conhecida, passou a atrair cada vez mais pessoas de todos os lugares e etnias. Esse fato possibilitou o fortalecimento de um partido de direita formado em 1966, o Shiv Sena, da etnia local, marata. Os conflitos étnico-religiosos vêm se intensificando desde 1992.

Entre 2006 e 2008, levas de atentados têm ocorrido na cidade. Para finalizar estes fragmentos de histórias de Bombaim, é interessante sabermos que em 
1995 o governo de Maharashta, conduzido pelo partido Shiv Sena, repudiou o nome Bombay em nome da versão marata Mumbai. Repúdio que nos leva ao conhecimento da etimologia da palavra e a uma antiga discussão entre lusófonos e anglófonos sobre o nome Bombaim/Mumbaim ou Bombay/Mombay.

Etimologicamente, as primeiras referências portuguesas datam de 1516. As grafias Benamajambu ou Terra-Maiambu são uma provável alusão a Mumba-Devi, deusa hindu de onde vem o nome local, em marata. A forma Mumbaim aparece no final do século XVI na obra de Gaspar Correia: Lendas da Índia ${ }^{10}$. Ao retomarmos a sequência em que os rapazes conversam no prédio em construção, o irmão aponta para o conjunto de prédios e chama a atenção de Jamal para o que fizeram com a Bombaim/Mumbai de suas infâncias.

Relembrando que o filme Quem quer ser um milionário? foi pensado como pretexto para estudar os cinemas da Índia, um dos pontos que poderíamos ressaltar - além das questões linguísticas, étnicas e políticas que não se separam nos contextos histórico e cinematográfico - é o da simultaneidade entre o desenvolvimento dos meios tecnológicos, a indústria do cinema e o temário. Com algumas variações de datas e processos, os cinemas regionais da Índia nasceram entre 1896 e 1927/28, com uma boa produção de filmes mudos, cuja temática era essencialmente religiosa, mística e moral.

Com a chegada do cinema falado, entre 1928 e 1934 até o início da Segunda Guerra, os temas puramente religiosos vão cedendo lugar aos assuntos sociais. A título de exemplos: em 1934, C. Pullaiah atrai o público jovem para o cinema quando aborda um dos temas caros ao cinema e à cultura indiana até hoje: o Ramayana ou a Epopeia de Rama, um épico da literatura védica da Índia Antiga junto com o Mahabharata, que em sânscrito significa $a$ grande história da humanidade. Em 1936, o filme Prema Vijayam, de Krithiventi Nageswara Rao, conta a história de dois jovens que querem casar-se contra a vontade dos pais, inaugurando os temas sociais e amorosos. Em 1939 aparece o primeiro filme que fala dos intocáveis e dos dotes familiares, questões polêmicas na cultura indiana.

A participação da Índia, como colônia britânica, na Guerra iniciada em 1939 provocou uma crise no cinema. Faltavam matérias-primas, foi proibida a construção de novas salas de exibição, além da censura inglesa ante o movimento desencadeado por Gandhi e Nheru, presos na ocasião. Conta-nos também Sadoul que Calcutá, bombardeada pelos japoneses que pretendiam entrar na Birmânia, diminuiu sua produção, que ficou abaixo dos cem filmes por ano ${ }^{11}$. A Guerra e a conquista da Independência em 1947 mudaram os destinos de alguns cinemas, especialmente o da região de Punjab, com a divisão e a criação do Estado do Paquistão para os muçulmanos.

Essa operação provocou uma migração de milhões de pessoas. Durante os motins foram destruídas salas de exibição; outras foram invadidas e inutilizadas pelos refugiados que nelas se alojavam. O trágico êxodo foi notavelmente descrito num filme bengali de Nemi Gosh, Os desenraizados; que se torna perturbador quando mostra uma mulher idosa, expulsa de sua terra natal, contar a sua tragédia ${ }^{12}$.
10. MACHADO, José Pedro. Dicionário onomástico etimológico da Língua Portuguesa. Lisboa: Livros Horizonte, 2003. p. 265-266, vol. I. 11. SADOUL, op. cit., p. 529.

12. Ibid. 
comunicação \& educação • Ano XIV • Número 3 • set/dez 2009

\section{OS CINEMAS MALAYALAM, KARNATAKA E TAMIL NADU}

Bengali era a língua de Tagore. Bengalês ou bengali é a língua falada em boa parte do leste, hoje dividida entre o West Bengal - cuja capital é Calcutá e abriga o bairro que sedia a indústria do cinema, o Tollygunge - e Bangladesh, que concentra sua produção em Daka, capital do país, também conhecida como Dhallywood.

A temática do cinema bengali, menos song-and-dance e mais próxima ao que se poderia chamar de artística, o diferenciou dos demais produzidos na Índia. Como todas as histórias dos povos, os cinemas não ficaram fora das mudanças globais ocorridas a partir dos anos 1980. No caso do cinema bengali, houve uma aproximação do cinema popular de Bollywood em detrimento de seu cinema social e artístico. Enquanto Bollywood sofreu influências diretas do cinema norte-americano, afirmando-se como a Hollywood indiana, a indústria cinematográfica de Tollywood é sua concorrente, e sua produção está instalada no estado de Andhra Pradesh.

Em Tollywood está o maior estúdio de cinema do mundo: a Ramoji Film City, criado em 1996, em uma área de $8 \mathrm{~km}$, além de possuir mais de 2700 salas de cinema, sendo 150 na capital de Andhra Pradesh, Hyderabad ${ }^{13}$. Outro aspecto do cinema telugu é a existência de uma produção independente, cujos diretores, além de manterem os temas sociais que sempre estiveram presentes nos seus filmes, introduzem outras temáticas, como Vanaja (2006), a história de uma menina que luta para aprender a dançar.

Embora o espaço aqui não seja para traçar uma história cronológica ou temática aprofundadas dos cinemas indianos, não podemos deixar de falar um pouco dos cinemas Malayalam, Karnataka e Tamil Nadu.

O cinema Malayalam, que fica no estado de Kerala, na costa sudoeste do país, nos interessa em muitos sentidos. Um deles é histórico. Brasil e Índia fizeram parte dos movimentos colonialistas e expansionistas iniciados no século $\mathrm{XV}$, e ambos tiveram seus territórios ocupados e controlados pelas potências europeias dominantes na época.

A descoberta das rotas marítimas para a Índia em 1498, pelo navegador

13. MACHADO, Ibirá. Sobre o cinema indiano. Disponível em: <http:// cinemaindiano.blogs pot.com/search/label/

Tollywood>. Acesso em: 3 nov. 2009.

14. Id. Sobre o cinema indiano. Disponível em: $<$ http://cinemaindiano. blogspot.com/2008/07/ cinema-malayalam.html >. Acesso em: 3 nov. 2009.

15. Ibid. Vasco da Gama, colocou Brasil e Índia nas rotas comerciais das especiarias. No intenso comércio da Era das Navegações, vale como curiosidade saber que Portugal trouxe para o Brasil o coco originário de Kerala e para lá levou o caju e a mandioca. O estado de Kerala se destaca na Índia por três características: as praias, a medicina ayurvédica e o socialismo ${ }^{14}$.

Se as duas primeiras atraem turistas, as temáticas sociais de seu cinema, desde sua origem, ganharam força nos anos de 1950, quando os filmes passaram a tratar de questões referentes às tradições familiares da Índia. Considerado mais realista que os filmes produzidos em Bollywood ${ }^{15}$, em 1955, o filme Newspaper Boys trouxe a história de um garoto que trabalhava em uma 
gráfica e de sua família extremamente pobre. Foi analisado como próximo do neorrealismo italiano.

Essa informação ou leitura chama a atenção para o fato de que os cinemas indianos só entraram em contato com outras cinematografias estrangeiras, excluindo Hollywood e os filmes ingleses, em 1952, quando foi realizado um Festival de Cinema europeu em Bombaim e Calcutá. Esse Festival é que “deu a conhecer aos homens do cinema indiano, com certas obras francesas e soviéticas, alguns filmes-chave do neorrealismo italiano"16.

Outra influência dos primeiros contatos entre os diretores indianos e estrangeiros pode ser acompanhada no cinema tâmil, em 1954, quando S. Balachander lançou o filme Antha Naal, totalmente dentro da estética do cinema noir e baseado na produção Rashômon, de Akira Kurosawa.

Como todos os cinemas indianos, o cinema do estado de Tamil Nadu data do começo do século, mais precisamente de 1909, passa pela fase do cinema mudo e lança seu primeiro filme falado, Kalidaas, em 1931, mesmo ano do híndi Alam Ara, considerado o primeiro filme falado da Índia. Em 1939, produziu o primeiro filme banido na história do cinema indiano: Thyagoboomi, do diretor K. Subramaniam, porque glorificava a luta de Mahatma Gandhi.

Há outros dados a serem considerados sobre o cinema tâmil, como: a preocupação da indústria com a técnica de direção; o centro de sua produção cinematográfica, para que se imponha não apenas no sul, onde está sediada a indústria cinematográfica tâmil ou popularmente conhecida de Kollywood, mas em toda a Índia; e o fato de suas produções serem refilmadas em outras indústrias, e o contrário também: muitos filmes de outras regiões são refilmados ou dublados em tâmil.

Se os anos de 1950 foram significativos para boa parte dos cinemas indianos, não podemos deixar de assinalar que em 1955 a Índia desempenhou um papel fundamental no conflito da Guerra Fria instituída desde 1945. Com o objetivo de discutir medidas comuns e estabelecer uma política de não alinhamento às políticas dos Estados Unidos e União Soviética, a Índia independente deu forma ao "Movimento dos Não Alinhados", cujas origens estavam na Conferência Afro-Asiática realizada em Bandung, na Indonésia.

Dos sete grandes estados indianos que sediam as principais indústrias cinematográficas do continente, Karnataka é um dos que ficam no sul da Índia e sua capital é Bangalore ou Bangaluru. A língua é o kannada, do tronco linguístico dravidiano, e a mesma falada em seu cinema. Como existe uma minoria tulu na região, uma parte da produção cinematográfica é feita em tulu e outra em konkani, língua dos vizinhos de $\mathrm{Goa}^{17}$. Karnataka é também um estado de muitas histórias. Uma delas é a de que produz o melhor sândalo do mundo e a outra, a de que Bangalore é a cidade mais globalizada da Índia. Justifica-se: a indústria cinematográfica de Bangalore é conhecida como Sandalwood, uma brincadeira relativa ao sândalo. A cidade abriga a Infosys Technologies, uma das mais bem-sucedidas empresas de software do mundo.
16. SADOUL, op. cit. p. 531.

17. MACHADO, Ibirá. Sobre o cinema indiano Disponível em: <http:// cinemaindiano.blogspot. com/search/label/Karnataka>. 
comunicação \& educação • Ano XIV • Número 3 • set/dez 2009

\section{COINCIDEM HISTÓRIA E CINEMA: AS DÉCADAS DE 1970 E 1980}

Os anos de 1970 e 1980 representaram para o cinema Kannada o ingresso ao que se passou a chamar de Nova Era do cinema, e para Bangalore o ingresso no processo da nova era da globalização.

Entre 1977 e 2007, a indústria do cinema cresceu em produção e incentivos fiscais para que a maior parte dos filmes fossem $100 \%$ produzidos no local. Em 2007, por exemplo, o filme Dunya foi lançado em outros países com colônias indianas, colocando o cinema Kannada no mundo ${ }^{18}$.

Em 1980 surgiu a Infosys, com um capital inicial de 300 dólares. Estruturada em quatro módulos - educação, tecnologia, recursos humanos e infraestrutura ${ }^{19}$-, tinha por objetivo, naquele momento, treinar e utilizar o grande número de engenheiros indianos como mão de obra barata para a então crescente indústria de software, ou seja, como processo já conhecido de terceirização ${ }^{20}$.

Levando-se em conta as 12 horas que separam Bangalore do Vale do Silício na Califórnia, as 24 horas diretas de produção de software e a transformação da Infosys de centro externo de desenvolvimento para a indústria de software americano, os indianos precisaram apenas de uma década para descobrir que, se desenvolvessem seu próprio software, também venderiam para todo o mundo.

A "Infosys mudou o nome para Infosys Technologies e construiu uma sede semelhante a um campus universitário fora de Bangalore, a Eletronics City" ${ }^{21}$, local para onde vão muitos jovens em busca de emprego. Diferentemente de outras épocas, quando sair da Índia para crescer economicamente era desejo de muitos, hoje eles preferem ficar na região. No início dos anos de 1980, de acordo com os dados de Srinivas,

[...] as famílias de Bangalore tinham pelo menos um membro de sua família em Dubai ou nos Estados Unidos. Mas hoje os indianos preferem permanecer na Índia, como disse um engenheiro de software: "Há vinte anos, se você quisesse crescer precisava ir para os Estados Unidos; hoje você pode ficar em casa e se tornar um milionário" $[\ldots]^{22}$.

As décadas de 1970/1980 colocaram Karnataka no contexto da globalização; a globalização econômica aumenta a esperança de que a economia indiana possa crescer e diminuir a pobreza; a globalização cultural é vista em todas as cidades "com gigantescos anúncios de Hyundai, MTV, computadores com chips Intel e Café Sunrise”"23; Bangalore é a cidade mais globalizada da Índia, onde as duas grandes forças globalizantes mais reconhecíveis, as multinacionais

18. Ibid.

19. SRINIVAS, op. cit.

p. 129.

20. Ibid.

21. Ibid.

22. Ibid., p. 131.

23. Ibid., p. 111. e a cultura popular segundo o modelo MTV, seduzem a classe média urbana.

Portanto, é necessário saber outros efeitos da globalização em Karnataka, mais especificamente, em Bangalore. Apenas para exemplificar: os agricultores ao redor de Bangalore já não plantam mais os produtos para consumo interno, somente os destinados ao mercado global, como flores perfumadas para o mercado francês e flores tropicais e pepinos para o mercado europeu e americano; entre dezembro de 1997 e maio de 1998, 23 agricultores de algodão cometeram 
suicídio, após terem investido em sementes estrangeiras e fertilizantes - sem conhecimento especializado, tiveram sua produção toda perdida; ou, ainda, a luta internacional em torno da patente do tempero de cúrcuma ${ }^{24}$.

Não sabemos se essas e outras histórias foram para as telas do cinema Kannada, como não sabemos se algum dos filmes conta a história do movimento naxalita, de tendência maoísta, que surgiu em março de 1967, quando os camponeses da aldeia de Naxalbari, em Bengala, se apoderaram do arroz de um proprietário rural. E tal movimento está em atividade até hoje, inclusive em Karnataka.

Karnataka, apesar de todo o desenvolvimento econômico e tecnológico, mostra, fora das telas de cinema, que a questão das castas continua permeada por tragédias, ao absolver 46 pessoas acusadas de queimar vivos sete intocáveis (dalits) na aldeia de Kambalapali, em dezembro de 2006.

Histórias locais em cenários globais podem compor uma extensa pesquisa sobre esse continente que, mesmo acostumado com o Ocidente e suas influências culturais, a ele também reage das mais diferentes formas: da aceitação híbrida à completa rejeição.

Em Bangalore, um jovem engenheiro já não precisa mais sair de sua cidade para se tornar um milionário. Mumbai, na Bollywood de Jamal, conhecida como uma das maiores indústrias de cinema e do entretenimento do mundo, nos dias atuais vem sofrendo a concorrência de um não menos popular veículo de massa: a televisão. Mumbai e a televisão foram o cenário e o meio usado por Boyle para contar como Jamal Malik conseguiu ficar milionário.

\section{ENTRE FICÇÕES E REALIDADES}

O filme Quem quer ser um milionário? também serve como pretexto para discutirmos essa realidade própria da história e da cultura indiana, esse movimento que vai da aceitação à rejeição das influências ocidentais.

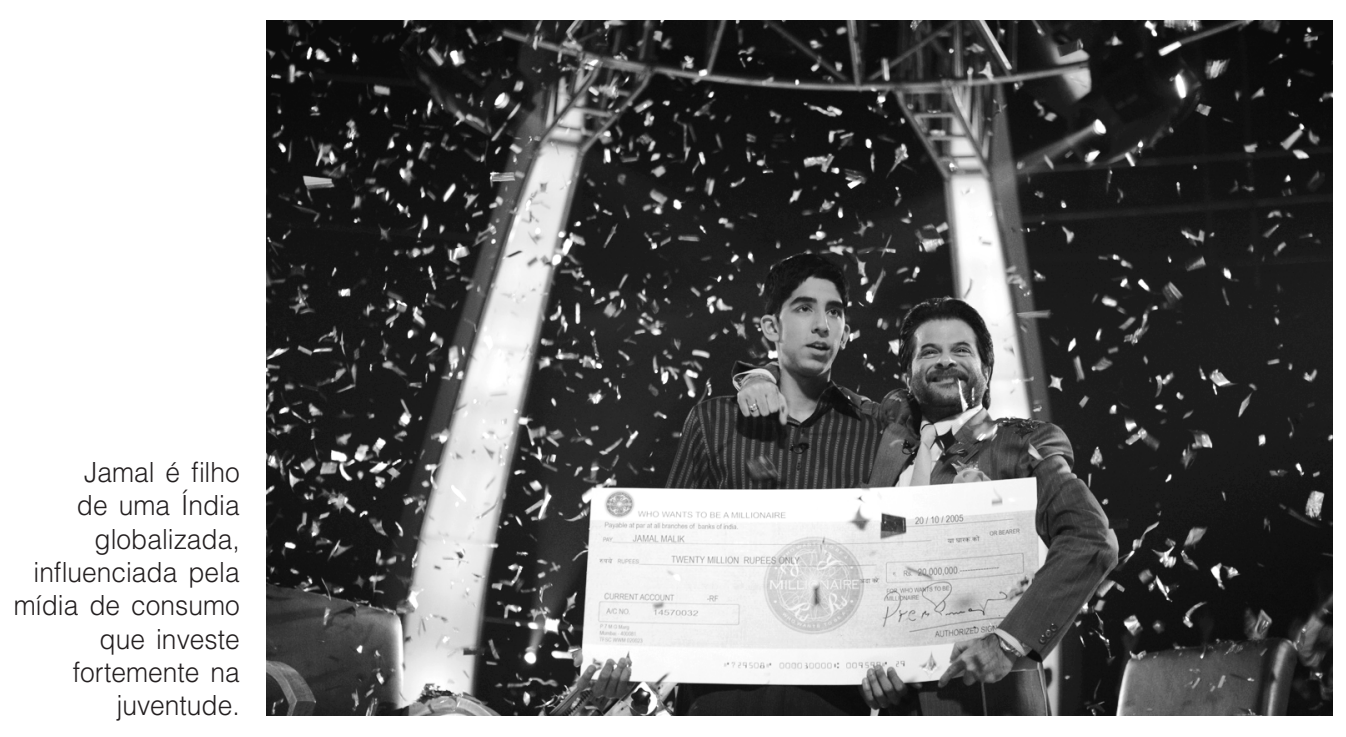


Um dos exemplos dessa mistura, influência e caminho próprio podem ser vistos nessa produção. Danny Boyle é inglês, realizou o filme com a assistência do cineasta indiano Loveleen Tandan e baseou-se na novela $Q \mathcal{E}$ A do escritor indiano Vikas Swarup e no popular programa de televisão inglesa. O filme foi rodado em Mumbai, sede de Bollywood - inspirada em Hollywood -, um dos maiores parques indústrias de cinema do mundo. Na Índia, onde o cinema é essencialmente indústria de entretenimento, o ator principal Dav Patel (Jamal Malik) veio da televisão, onde foi por várias vezes premiado por suas atuações.

Na ficção, o jovem que interpreta veio das favelas de Mumbai e, apesar da pobreza, é dono de uma memória extraordinária, não porque a exercitou, mas porque é parte de sua vivência, e graças a ela se tornou milionário no programa de TV; graças a ela e à ajuda de outras tecnologias e meios de comunicação, como a internet e o celular. Afinal, Jamal era funcionário de uma empresa multinacional de telemarketing, inscreveu-se em um programa de TV local e é salvo no último momento por uma ligação de celular.

Jamal/Dav são filhos de uma Índia globalizada, em franco desenvolvimento econômico, influenciada pela mídia de consumo que investe fortemente na juventude e em seu modo de vestir, por onde circular, que música ouvir, como exemplifica Srinivas, em seu estudo sobre a globalização cultural na Índia: "Um pastiche de vestuário de inspiração indiana e piadinhas ao estilo americano ditas em um inglês com sotaque de Oxbridge, intercalado com diálogos que parecem saídos de uma produção da Hindi Films, é a norma para os apresentadores da TV indiana"25.

Filhos de uma Índia que, ao mesmo tempo que aceita a entrada de grandes capitais estrangeiros, desconfia de todas as propagandas do McDonald's e rejeita seus lanches porque, entre vários motivos, não têm sabor, mesmo para os adolescentes que continuam preferindo o bolinho de carne de carneiro do restaurante indiano; sem esquecer a rejeição dos vegetarianos ao lanche McDonald's, apesar de toda tentativa de indianizar o cardápio.

Filhos de uma Índia antropófaga que assimila, deglute e devolve tudo segundo suas próprias raízes, de uma cultura que não "desaprova as práticas de consumo do padrão global, tanto em níveis de consumo produtivo como não produtivo [...] mas cria a política dos substitutivos como a força operadora: substitui em nível de produtores e as marcas são sua estratégia" ${ }^{26}$.

Como exemplos: em vez do creme dental Colgate, um produto multinacio-

26. NAGARAJ, D. R. O

hindu ansioso e o fazendeiro zangado: notas sobre a cultura e a política de duas reações à globalização na Índia. In: MENDES, Candido (Coord.). Pluralismo cultural, identidade e globalização. Rio de Janeiro: Record, 2001. p. 284 nal, os indianos são incentivados a comprar um produto local, o creme dental Vajradanti. Ou, no caso do McDonald's, o Maharajah Mac, um hambúrguer indiano, com vários itens vegetarianos.

Malik e Tagore são filhos de uma cultura difícil de ser entendida e discutida no contexto de uma única globalização, porque são inúmeras as diferenças internas, como as castas, a religião, as etnias, as classes, as seitas, as regiões. 
E por que não é possível falar por toda a Índia com uma só voz, por ela ser densa e múltipla, por estar além do puramente exótico ou bélico, como pudemos acompanhar nestes breves exemplos, é que propomos este filme.

Retomando todos os fragmentos histórico-cinematográficos trazidos, e pensando nessa cultura que oscila entre a aceitação e a rejeição das influências externas, acredito que uma das reflexões interessantes seja a de tentar descobrir como o cinema e a indústria cinematográfica da Índia podem se inserir neste contexto?

A história de Bollywood pode ser um bom começo para discutir até que ponto os Wood de todos os cinemas regionais da Índia são influências estéticas e narrativas de Hollywood ou referências de um modelo industrial?

A questão está lançada para quem se aventurar a decifrá-la. O final pode não fazer nenhum milionário, mas, com certeza, fará um ganhador de conhecimentos sobre esse cinema tão intrigante como o país de Tagore e Malik. No encontro da poesia com a técnica, que tornou possível o cinema que sempre existiu na cabeça dos homens, entender: a história e a mágica que os olhos tanto gostam de ver e ouvir.

\title{
REFERÊNCIAS BIBLIOGRÁFICAS
}

\author{
MACHADO, José Pedro. Dicionário Onomástico Etimológico da Língua \\ Portuguesa. Livros Horizonte, 2003. v. I.
}

NAGARAJ, D. R. O hindu ansioso e o fazendeiro zangado: notas sobre a cultura e a política de duas reações à globalização na Índia. In: MENDES, Candido (Coord.). Pluralismo cultural, identidade e globalização. Rio de Janeiro: Record, 2001.

NAGIB, Lucia. Rumo a uma definição positiva de World Cinema. In: SANTANA, Gelson (Org.). Cinema, comunicação e audiovisual. São Paulo: Alameda, 2007.

SADOUL, Georges. História do cinema mundial. Lisboa: Livros Horizonte, 1983. v. III.

SRINIVAS, Tulasi. Um encontro com o destino: globalização cultural na Índia. In: BERGER, Peter L.; HUNTINGTON, Samuel P. (Coord.). Muitas globalizações. Rio de Janeiro: Record, 2004.

\section{Endereços eletrônicos}

MACHADO, Ibirá. Sobre o cinema indiano. Disponível em: <http:// cinemaindiano.blogspot.com/2008/09/curiosidades-as-diferentes-lnguas-e. html $>$. Acesso em: 3 nov. 2009. 
. Sobre o cinema indiano. Disponível em: $<$ http:/ / cinemaindiano.blogspot. com/search/label/Tollywood>. Acesso em: 3 nov. 2009.

. Sobre o cinema indiano. Disponível em: $<$ http:/ / cinemaindiano.blogspot. com/2008/07/cinema-malayalam.html $>$. Acesso em: 3 nov. 2009.

. Sobre o cinema indiano. Disponível em: $<$ http:/ / cinemaindiano.blogspot. com/search/label/Karnataka>. Acesso em: 3 nov. 2009.

RABINDRANATH, Tagore. Coletânea de poesias. Disponível em: <http://www. cuidardoser.com.br/coletanea-tagore.htm $>$. Acesso em: $<$ http:/ /quemquerserum milionario.uol.com.br/>.

VIKAS SWARUP. Disponível em: <http:/ /www.asa.pt/autores/autor.php?id=1929>. 